\title{
Composite bioceramics/polymer electrospun scaffolds for regenerative medicine
}

\author{
T. Miramond ${ }^{1,2 a}$, P. Borget ${ }^{2 b}$, C.Colombeix ${ }^{1 \mathrm{c}}, \mathrm{S}$. Baroth $^{2 \mathrm{~d}}$, and G. Daculsi ${ }^{1 \mathrm{e}}$ \\ ${ }^{1}$ INSERM Nantes University, Dental Faculty, place A. Ricordeau 44042 Nantes France; \\ ${ }^{2}$ Biomatlante SA, 5 rue Edouard Belin, 44360 Vigneux de Bretagne France' \\ athomas.miramond@etu.univ-nantes.fr, bpascalborget@biomatlante.com, \\ ccaroline.colombeix@univ-nantes.fr, ${ }^{d}$ sergebaroth@biomatlante.com, ${ }^{\mathrm{c}}$ guy.daculsi@univ-nantes.fr
}

Keywords: Fibers, biphasic calcium phosphate, composite, scaffold, cell adhesion

\begin{abstract}
.
The main goal of this study was to succeed in the relevant association of well-known osteoconductive biphasic calcium phosphate (BCP) made of Hydroxyapatite (20\% HA) and $\beta$ Tricalcium Phosphate $(80 \% \beta$-TCP) crystallographic phases and resorbable poly(L-lactide-co-D,Llactide)(PLDLLA) 3D matrices synthesized by electrospinning. Two types of mineral particles were obtained, BCP new hollow granules, and classical BCP particles. It appeared that hollow shells/PLDLLA composite 3D matrices allowed higher cell adhesion in vitro, thanks to internal concavities and are promising scaffolds in terms of cell carrying.
\end{abstract}

\section{Introduction}

The need of both bioresorbable and osteoconductive 3D scaffolds able to recruit stem cells and enhance their differentiation to new bone, lead to innovative composite biomaterials synthesis for bone tissue engineering and gene therapy [1]. Electrospinning is a room temperature process invented in 1934 [2] involving nano or micro fibers-based scaffolds able to be used for bone ingrowth as literature mentioned it since the late $90 \mathrm{~s}[3,4]$. Its biomimetic properties regarding extracellular matrix microstructure similarities enhanced cell attachment and adhesion [5-7] and justified this method to design fiber-based 3D scaffolds [7, 8]. One-step electrospinning process is then considered as a promising technology for regenerative medicine since it is low-cost, rapid and easy to perform [9]. Among all the available polymers in bone tissue engineering, such as polycaprolactone (PCL) or poly(lactic acid-co-glycol acid) (PLGA) [10, 11], poly(L-lactide-coD,L-lactide)(PLDLLA) which is part of poly ( $\alpha$-hydroxyacids) family [12], was selected in our development according past studies results dealing with combination of BCP microparticles and PLDLLA for the elaboration of resorbable osteosynthesis with osteogenic properties [13-15].

As fiber -based scaffold need osteoconductive component to match bone tissue engineering specifications[16], addition of microparticles of hydroxyapatite (HA) or tricalcium phosphate $(\beta-$ TCP) [17] to electrospun scaffolds have been shown to be relevant not only in term of cell adhesion enhancement, but also in cell differentiation involving extracellular matrix mineralization [18-20]. In this study biphasic calcium phosphate (BCP) new galenic formulation, that we called Hollow Shells, with a ratio HA/TCP of 20/80 were synthesized using specific granulation method so as to obtain a composite ceramic granule/3D fibers containing either macroscopic hollow shells or classical microscopic particles. Osteoconductive properties of these BCP biomaterials have been proven for decades [21, 22] and resorption-precipitation mechanism involved in vivo have been explained to be favorable to osteoinduction $[23,24]$.

\section{Materials and Methods}

Poly(L-lactide-co-D,L-lactide) was obtained from Biomatlante SA (Vigneux-de-Bretagne, France). After synthesis and sintering, hollow shells were passed through sieves in order to obtain granules $(400$ to $600 \mu \mathrm{m})$ and BCP microparticles of size less than $10 \mu \mathrm{m}$. 
Thus two kinds of BCP were incorporated into the 3D scaffolds in two ways. In the first one, BCP microparticles were mixed with the polymer solution which was PLDLLA dissolved in choloroform at $4 \% \mathrm{w} / \mathrm{v}$ [25], and then projection was realized by electrospinning. The second one consisted on deposition on aluminium conductive support, of macroscopic granules called "hollow shells" being embedded during the electrospinning process.

The electrospinning device (Linarii Bioengineering, Italia) was set at $25 \mathrm{kv}$, with a working distance of $20 \mathrm{~cm}$ and a flow of $5 \mathrm{cc} /$ hour.

Three types of membranes were synthesized using PLDLLA:
A. Polymer alone
B. Composite Polymer/Bioceramic with macroscopic BCP hollow shells
C. Composite Polymer/Bioceramic with microscopic classical BCP particles

Scanning Electron Microscopy (SEM) Fitted with Energy Dispersive X-Ray (EDX) were performed to localize BCP microparticles. Image analysis for fibers diameter was realized by manually measurement of pictures $(n=5)$ for each kind of 3D scaffold. Density calculation were realized.

Cell adhesion assessment on membranes A, B and C was realized using MC3T3 osteoblastic murine cells after 3 days in contact of membranes in alpha MEM culture medium (10\% Foetal bovine serum, $1 \%$ streptomycin/penicillin, $1 \%$ L-glutamin). Cells were fixed with paraformaldehyde (4\% in phosphate buffer saline) then the immune-independent actin marker phalloidin (Sigma-Aldrich) have been incorporated to the seeded cells after using a permeabilization buffer (Tween $0.05 \%$, BSA 3\% in PBS). Nucleus staining was obtained thanks to Topro-3 DNA dye (Invitrogen). Stained cells were then observed in situ using fluorescent and confocal microscopy, in order to determine cells density and cells morphology.

\section{Results}

Hollow shells were observed after sintering and before electrospining process. A large macropore concavity (figure 1a) appeared in each granule with a diameter of between $300 \mu \mathrm{m}$ to $500 \mu \mathrm{m}$ and high microporosities content less than $1 \mu \mathrm{m}$ (figure 1b).

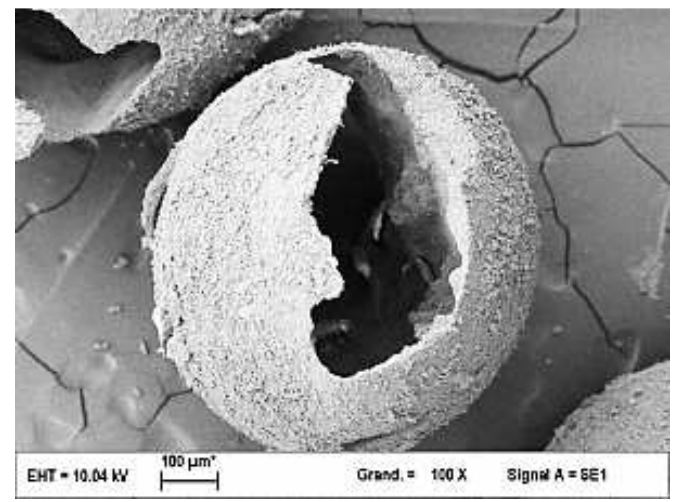

(a)

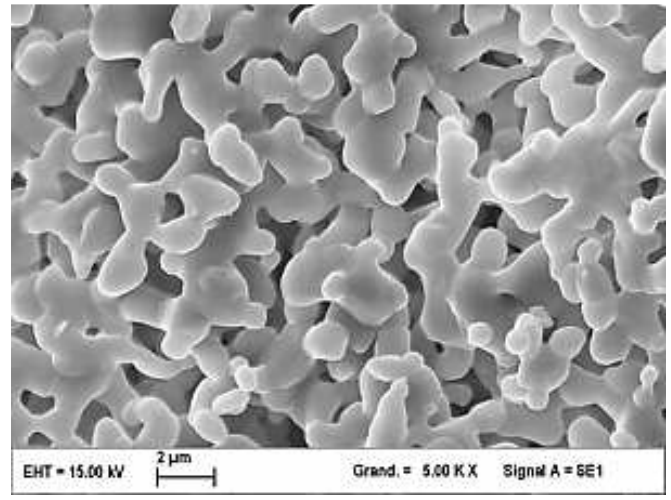

(b)

Figure 1: Hollow Shells characterization before electrospinning process

Electrospun fibers of all membranes types (A, B, C) were found to have a bimodal distribution of their diameters, fiber diameters $4 \mu \mathrm{m}$ (class I) and fiber diameters $1 \mu \mathrm{m}$ (class II) as seen in figure 2 . Hollow shells of type B scaffolds were embedded in lower density of fibers comparing to the rest of the scaffold (figure 2b), with a round area around hollow shells of approximately $500 \mu \mathrm{m}$ in diameter. 
(a)

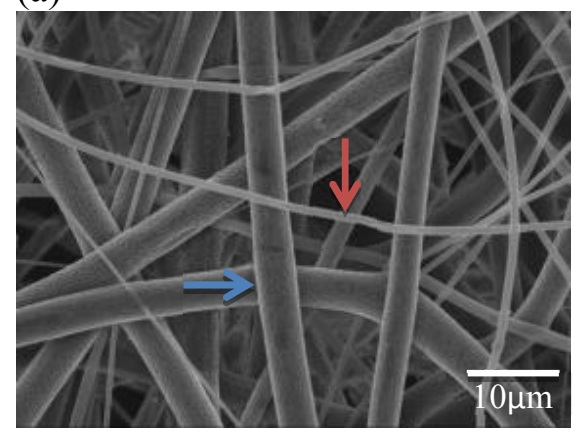

(b)

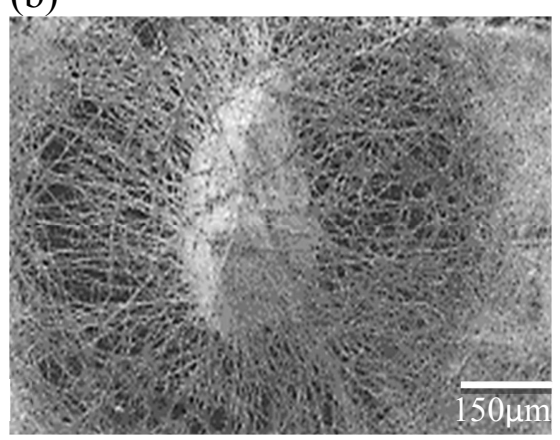

(c)

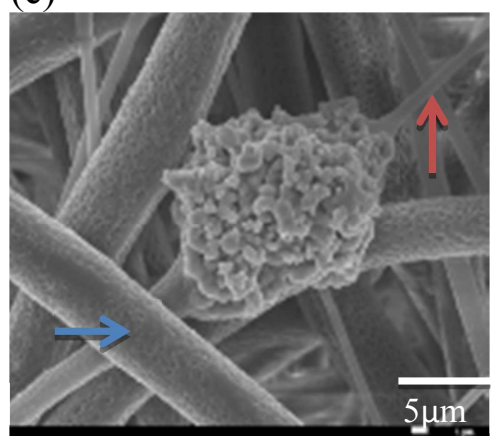

Figure 2: (a) sample A; ( b) sample B Hollow Shells; (c) sample C with BCP micro particles. Arrows : class I (blue) and class II (red)

BCP Micro particles of membranes type $\mathrm{C}$ were localized by EDX cartography and appeared to be partially encapsulated into fibers leaving the grains and micropores appear (figure $2 \mathrm{c}$ ). It was pointed out that only fibers of class II contained BCP micro particles (figure 2c). Qualitative EDX spectra of BCP particles confirmed the presence of calcium and phosphate without any contaminants (figure 3).

Figure 3: Qualitative Energy Dispersive X-Ray (EDX) spectra of BCP microparticles (arrow) in scaffold $C$ showed only $C a$ and $P$

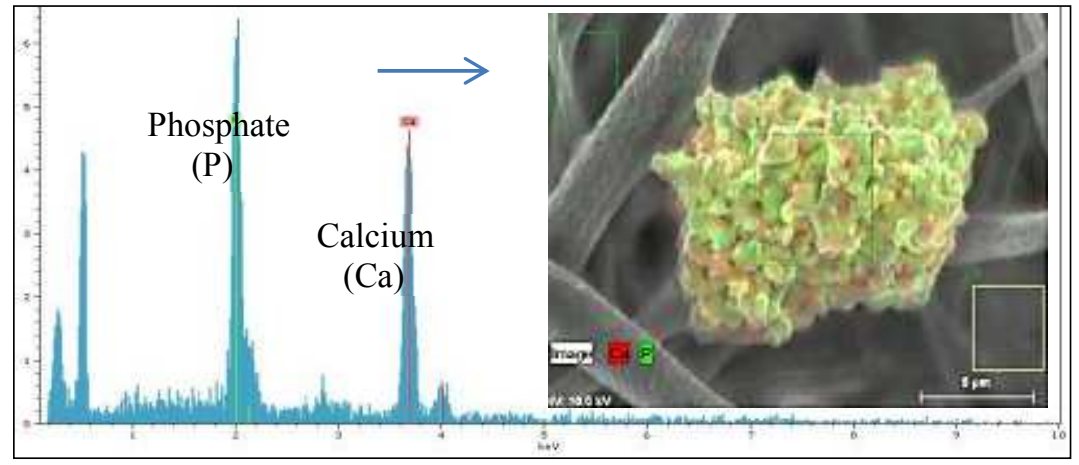

For all types of scaffolds, only class I fibers were characterized as microporous, and image analysis was performed to evaluate surface porosity of these fibers (figure 2 and figure 4). Surface intraporosity of class I fibers were calculated as between 10 and $15 \%$. Class II thinner fibers presented almost none porosity. The density of all samples was $0.3 \mathrm{~g} / \mathrm{cm}^{3} \pm 0.05$, interporosity between the fibers was calculated from density and rounded to $75 \%$ for all scaffolds types.

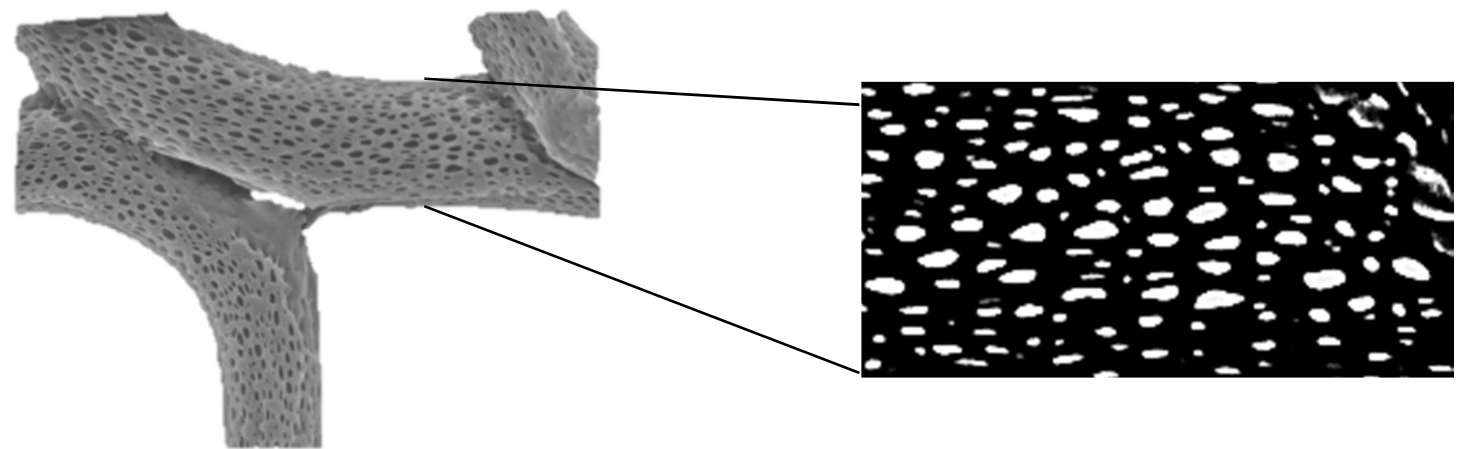

Figure 4: Image analysis of class I fiber surface intraporosity

Confocal microscopy observations of living cells adhering to scaffolds shown two main differences between samples A, C and sample B. The first one was the cell density, which appeared higher inside hollow shells than on fibers (figure 5c). The second one was the cell morphology, filiforms cells were extended along the fibers (figure $5 \mathrm{a}$ and $5 \mathrm{~b}$ ) while much more spreaded inside hollow shells as shown in figure $5 \mathrm{c}$. 
(a)

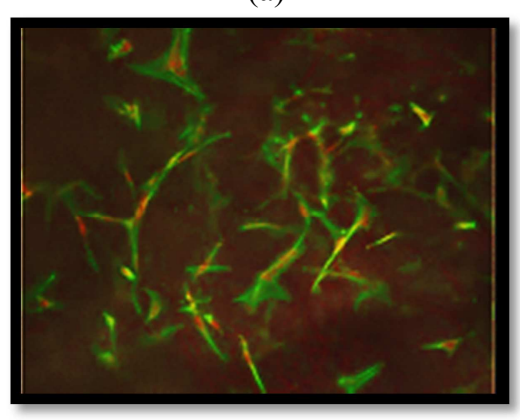

(b)

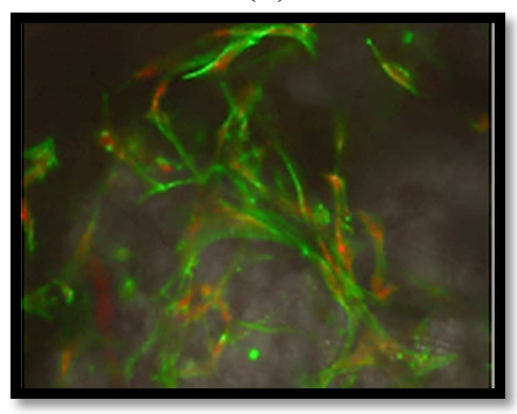

(c)

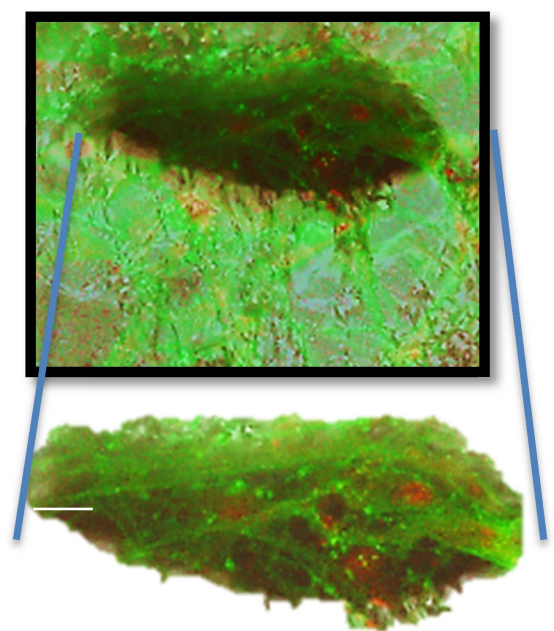

Figure 5: Filiform cells adhering on fibers of samplee $A(a)$, sample $B(b)$, and spreading in hollow shells of sample $C(c)$ at day 3

\section{Discussion}

Confocal microscopy observations enabled us to conclude PLDLLA fiber scaffolds are favorable to cell adhesion and proliferation with cell guidance along fibers leading to filiform morphology [26].

The incorporation of BCP micro particles in the polymeric solution lead to alter the homogeneity of the latter and thus disrupt the stability of the Taylor cone at the time of passage of particles through the needle of the syringe. This results in a decrease of the fiber diameter containing the ceramic micro particles. The slight increase in which that did not contain it due to higher magnitude of fluctuation of Taylor cone [27]. This fluctuation phenomenon is the cause of non-homogeneity of fibers diameters observed in this study (class I and class II fibers) [28].

The advantages of embedded BCP hollow granules in PLDLLA electrospun scaffolds are related to the seminal role of macropore concavities in adhesion and cell protection [29-31]. This specific properties combined to microporosity known to enhance proteins adhesion and body fluids penetration $[32,33]$. The only matter is to provide better homogeneity around non-conductive ceramic hollow shell which lead to lower fiber density areas as shown in this study. Moreover the high micrometric diameters of obtained fibers involved a better flexibility but a lower tensile strength than nanofibers [34].

\section{Conclusion}

Electrospinning has been demonstrated to be a low-cost, fast and easy one-step process to perform promising 3D composite fiber-based scaffolds with cell adhesion and protection enhancement thanks to new Hollow Shells incorporation.All membranes were flexible and easy to handle which are assets to provide relevant scaffolds for clinical purposes particularly in regenerative medicine.

\section{Acknowledgments:}

The research leading to these results has received funding from the European Union's 7th Framework Programme under grant agreement no FP7-HEALTH-2009-241879 (REBORNE) and no NMP3-SL-2010-245993 (GAMBA). Authors would like to thank Nicolas Stéphant and Paul Pilet for their help to this work. 


\section{References}

[1] Murugan, R. and S. Ramakrishna, Nano-featured scaffolds for tissue engineering: a review of spinning methodologies. Tissue engineering, 2006. 12(3): p. 435-447.

[2] Formhals, A., Process and apparatus for preparing artificial threads: US, 1975504, 1934.

[3] Huang, Z.M., et al., A review on polymer nanofibers by electrospinning and their applications in nanocomposites. Composites science and technology, 2003. 63(15): p. 22232253.

[4] Laurencin, C.T., et al., Fiber based tissue engineered scaffolds for musculoskeletal applications: in vitro cellular response. 1998. 550: p. 127.

[5] Nisbet, D., et al., Review paper: a review of the cellular response on electrospun nanofibers for tissue engineering. Journal of biomaterials applications, 2009. 24(1): p. 7-29.

[6] Kim, T.G. and T.G. Park, Biomimicking extracellular matrix: cell adhesive RGD peptide modified electrospun poly (D, L-lactic-co-glycolic acid) nanofiber mesh. Tissue engineering, 2006. 12(2): p. 221-233.

[7] Ramakrishna, S., et al., Science and engineering of electrospun nanofibers for advances in clean energy, water filtration, and regenerative medicine. Journal of materials science, 2010. 45(23): p. 6283-6312.

[8] Liao, S., et al., Biomimetic electrospun nanofibers for tissue regeneration. Biomedical Materials, 2006. 1: p. R45.

[9] Li, J., et al., A one-step method to fabricate PLLA scaffolds with deposition of bioactive hydroxyapatite and collagen using ice-based microporogens. Acta biomaterialia, 2010. 6(6): p. 2013-2019.

[10] Khan, N., Applications of electrospun nanofibers in the biomedical field. Studies by Undergraduate Researchers at Guelph, 2012. 5(2): p. 63-73.

[11] Pham, Q.P., U. Sharma, and A.G. Mikos, Electrospinning of polymeric nanofibers for tissue engineering applications: a review. Tissue engineering, 2006. 12(5): p. 1197-1211.

[12] Hollander, A.P. and P.V. Hatton, Biopolymer methods in tissue engineering. Vol. 238. 2004: Humana Pr Inc.

[13] Jouan, G., et al., PL DLLA Calcium Phosphate Composite Combined with MBCP Gel® for New Surgical Technologies: Resorbable Osteosynthesis and Bone Substitute. Key Engineering Materials, 2008. 361: p. 571-574.

[14] Jouan, G., et al., PL DLLA Calcium Phosphate Composite Combined with Macroporous Calcium Phosphate Cement MCPC ${ }^{\circledR}$ for New Surgical Technologies Combining Resorbable Osteosynthesis and Injectable Bone Substitute. Key Engineering Materials, 2008. 361: p. 411414.

[15] Borget.P. PLA/BCP granules composites for resorbable osteosynthesis: Preclinical and first clinical data. in 9th World Biomaterials Congress. 2012. Chengdu, China.

[16] Dorozhkin, S.V., Bioceramics of calcium orthophosphates. Biomaterials, 2010. 31(7): p. 1465-1485.

[17] Lam, C., et al., Mechanical and in vitro evaluations of composite PLDLLA/TCP scaffolds for bone engineering. Virtual and Physical Prototyping, 2008. 3(4): p. 193-197.

[18] Gupta, D., et al., Nanostructured biocomposite substrates by electrospinning and electrospraying for the mineralization of osteoblasts. Biomaterials, 2009. 30(11): p. 2085-94.

[19] Guan, D., et al., Attachment, proliferation and differentiation of BMSCs on gasjet/electrospun nHAP/PHB fibrous scaffolds. Applied Surface Science, 2008. 255(2): p. 324327.

[20] Chen, J., B. Chu, and B.S. Hsiao, Mineralization of hydroxyapatite in electrospun nanofibrous poly (L-lactic acid) scaffolds. Journal of Biomedical Materials Research Part A, 2006. 79(2): p. 307-317.

[21] G. Daculsi, N.P., S. Martin, J.C Le Nihouannen, V. Brulliard, J. Delecrin, B. Kerebel, $A$ comparative study of bioactive calcium phosphate ceramics after implantation in cancellous bone in the dog. The French Journal of Orthopaedic Surgery 1989. 3: p. 43-48. 
[22] Royal F. Ellinger, E.B.N., Kenneth L. Lynch, Histological assessment of periodontal osseous defects following implantations hydroxyapatite and biphasic calcium phosphate ceramics : a case report. The International Journal of Periodontics and Restorative Dentistery 1986.

[23] Kokubo, T., H.M. Kim, and M. Kawashita, Novel bioactive materials with different mechanical properties. Biomaterials, 2003. 24(13): p. 2161-2175.

[24] LeGeros, R.Z., Properties of osteoconductive biomaterials: calcium phosphates. Clin Orthop Relat Res, 2002(395): p. 81-98.

[25] Gizdavic-Nikolaidis, M., et al., Electrospun Functionalized Polyaniline Copolymer-Based Nanofibers with Potential Application in Tissue Engineering. Macromolecular bioscience, 2010. 10(12): p. 1424-1431.

[26] Badami, A.S., et al., Effect of fiber diameter on spreading, proliferation, and differentiation of osteoblastic cells on electrospun poly (lactic acid) substrates. Biomaterials, 2006. 27(4): p. 596-606.

[27] Theron, S., E. Zussman, and A. Yarin, Experimental investigation of the governing parameters in the electrospinning of polymer solutions. Polymer, 2004. 45(6): p. 2017-2030.

[28] Sigmund, W., et al., Processing and structure relationships in electrospinning of ceramic fiber systems. Journal of the American Ceramic Society, 2006. 89(2): p. 395-407.

[29] Richart, O., M. Descamps, and A. Liebetrau, Macroporous calcium phosphate ceramics: Optimization of the porous structure and its effect on the bone ingrowth in a sheep model. Key Engineering Materials, 2000. 192: p. 425-428.

[30] O. Gauthier, D.B., G. Grimandi, E. Aguado, J.M. Bouler, P. Weiss, G. Daculsi Bonegrafting of canine extraction sockets with an injectable calcium phosphate biomaterial. Bioceramics, 1998.

[31] Ripamonti, U. and L. Roden, Biomimetics for the induction of bone formation. Expert Rev Med Devices, 2010. 7(4): p. 469-79.

[32] Habibovic, P., et al., 3D microenvironment as essential element for osteoinduction by biomaterials. Biomaterials, 2005. 26(17): p. 3565-75.

[33] Le Nihouannen, D., et al., Ectopic bone formation by microporous calcium phosphate ceramic particles in sheep muscles. Bone, 2005. 36(6): p. 1086-1093.

[34] Wong, S.C., A. Baji, and S. Leng, Effect of fiber diameter on tensile properties of electrospun poly (-caprolactone). Polymer, 2008. 49(21): p. 4713-4722 